\title{
Aspects of the Morphology and Melting Behavior of Constrained Polyethylene Fibers
}

\author{
Jason Teckoe, David Clifford Bassett, and Robert Hamilton Olley \\ J. J. Thomson Physical Laboratory, University of Reading, \\ Reading RG6 6AF, U.K.
}

(Received January 11, 1999)

\begin{abstract}
The internal microstructure of a high performance polyethylene fiber, both as received and after heating, has been investigated by electron microscopy following permanganic etching. There is longitudinal fibrosity extending over many $\mu \mathrm{m}$ but, in common with other high performance fibers, this is accompanied by internal lateral cratering on the scale of $\sim 1 \mu \mathrm{m}$. The craters, which are a response to preferential penetration by the etchant into regions of reduced density and high free volume related to processing conditions, are centered on the first regions to melt. Melting of constrained fibers is from the hexagonal phase to an ordered melt which relaxes making the hexagonal phase unstable. The internal fiber/melt interfaces then move outwards from these centers towards the higher melting regions. Those which melt last are the intersections of the etched surface with surviving crater walls but appear as spines many $\mu \mathrm{m}$ long. They are almost certainly the remnants of the initial entangled molecular network which sustained the stress of processing in accordance with the new model of fiber structure.

KEY WORDS Morphology / Polyethylene / High Modulus Fibers / Electron Microscopy / Thermal Analysis /
\end{abstract}

One of the consequences of molecular chainfolding is that the continuity of covalent bonds along the chain axis is interrupted to the detriment of the macroscopic modulus and strength of crystalline polymers and specifically fibers made therefrom. ${ }^{1,2}$ To optimize these properties one needs, in principle, to use polyethylene because it contains the most chains per unit area and to increase the covalent continuity of a highly oriented sample by decreasing the proportion of chainfolding as far as possible while retaining sufficient crack-blunting ability to provide adequate toughness against fibrillation. In the event several high performance polyethylene fibers have become available, prepared in various ways but all containing molecules in highly extended conformations. However, the nature of the actual internal organization within these and other polymer fibers is not well understood. Longitudinal continuity has been at the forefront of discussion ${ }^{3}$ but recent microscopic examination has revealed novel lateral disordering in high performance polyethylene fibers ${ }^{4}$ and others examined-but with characteristic differences for different materials-and led to a new model of fiber structure. ${ }^{5}$

The essence of this model is that, during processing, the network of entangled molecules-which must exist to sustain the applied stress-is stretched out along the fiber axis. Extended portions act as nuclei for further crystallization which will then take place within a more or less rigid framework. In consequence the contraction which crystallization brings will impose a lateral tensile stress on subsequent solidification tending to decrease its density and to add free volume to the later-crystallizing regions which in due course allows them to melt ahead of their earlier-crystallizing surrounds. This suggestion has been confirmed in detail for Certran, formerly Tenfor, polyethylene fibers constrained by compaction. For them, partial melting and recrystallization has been shown to concentrate the free volume into a central, longitudinal hole. ${ }^{6}$ In this paper we are able to add to this model by examining the morphology of differential melting within individual constrained Tekmilon fibers using the methodology introduced by Tsubakihara et al. ${ }^{7,8}$ This is a system which melts with a narrower endotherm and at higher temperatures than Certran fibers; nevertheless, their melting morphologies are qualitatively similar. Constrained Tekmilon fibers enter the hexagonal phase $^{9}$ before melting ${ }^{7,8,10,11}$ to what must be an ordered melt. When this relaxes the hexagonal phase is rendered unstable and the regions of internal melting widen isothermally. The highest melting regions are walls $\sim 1 \mu \mathrm{m}$ apart which extend for many $\mu \mathrm{m}$ along the fiber axis, appearing as spines in cross-section. They are identified with the locations of the initial extended molecular network.

\section{EXPERIMENTAL}

The polyethylene fiber used in this study is a commercially available high modulus fiber whose properties are shown in Table I. Its morphologies, in longitudinal and transverse section, as received and after annealing treatments as described below, have been investigated using scanning (SEM) and transmission (TEM) electron microscopy following permanganic etching.

Melting characteristics were recorded in a PerkinElmer DSC-2C differential scanning calorimeter for both constrained and unconstrained samples. All DSC data have been corrected for scan rate and sample mass using a computer program developed in-house. In the constrained melting experiments, high modulus poly-

Table I. Details of Tekmilon fiber

\begin{tabular}{ccccc}
\hline Fiber & Processing type & Manufacturer & $\frac{M_{w}}{\mathrm{~kg} \mathrm{~mol}^{-1}}$ & $\begin{array}{c}\text { Tensile } \\
\text { modulus }\end{array}$ \\
\cline { 3 - 5 } Tekmilon & Melt-kneaded & $\begin{array}{c}\text { Mitsui } \\
\text { Petrochemical }\end{array}$ & 700 & 62 \\
& & & \\
\hline
\end{tabular}




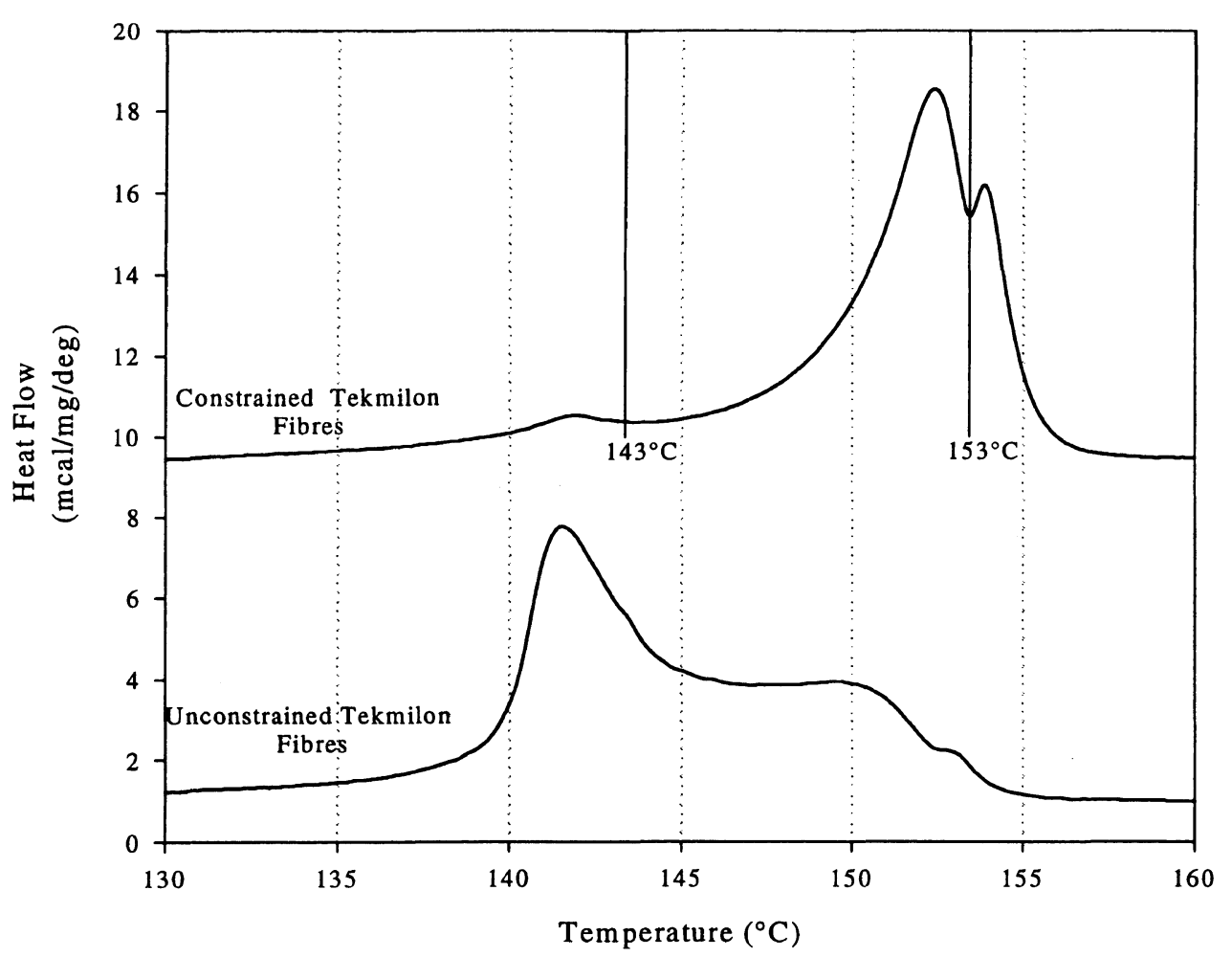

Figure 1. Melting endotherms for unconstrained and constrained Tekmilon fibers.

ethylene fibers were tightly wound around a copper spool, designed to fit in the sample pan of the calorimeter. ${ }^{7,8}$ Unconstrained samples had the fibers loosely wound into a ball within a DSC pan (with no copper spool). All samples for morphological examination were heated at a scan rate of $1.25 \mathrm{~K} \mathrm{~min}^{-1}$, a relatively low value, in order to reduce the effect of thermal inertia during heating. When the sample reached the required temperature and had been held there for the chosen time, the pan containing the spool and fibers was rapidly removed from the DSC usually to be immersed immediately in liquid nitrogen. The exceptions were when cooling in the DSC (at $160 \mathrm{~K} \mathrm{~min}^{-1}$ ) was employed to ascertain the consequences of an alternative cooling procedure. In all cases once the pan had returned to ambient temperature or below it was retrieved, opened carefully and the spool removed.

Once released from the spool, fibers were embedded in a block copolymeric elastomer (Kraton $\mathrm{G}$ ) prior to being cryo-microtomed at $-70^{\circ} \mathrm{C}$ to allow a representative internal surface to be exposed. This procedure was performed for both longitudinal and transverse sections. The samples were then etched for $1 \mathrm{~h}$ in a $1 \%$ solution of potassium permanganate in a $10: 4: 1$ (by volume) mixture of concentrated sulphuric acid, orthophosphoric acid $(85 \%)$, and water. The relevant etched surface was either replicated or gold coated using standard procedures according to whether TEM or SEM was to be used for their examination.

\section{RESULTS AND DISCUSSION}

\section{Effect of Constraint on Fiber Melting Characteristics}

The melting curves for constrained and unconstrained Tekmilon fibers are shown in Figure 1; evidently con- straint has a significant effect on the melting properties of the samples as has long been appreciated. ${ }^{12}$ With fibers simply rolled into a ball and placed in a DSC pan, the main melting peak is at a temperature of $141.6^{\circ} \mathrm{C}$ appropriate to unconstrained chain-extended polyethylene when the depression due to finite lamellar thickness is negligible. The higher melting point of fibers held at constant length is a consequence of the increased ordering of a highly aligned melt. ${ }^{12}$ This decreases its entropy, raises its Gibbs free energy and, for a sufficiently-extended system, also allows the usual orthorhombic phase of polyethylene to transform to the twodimensional hexagonal phase prior to final melting.

These two features are present in both melting endotherms of Figure 1. The constrained fibers show a small peak at $\sim 142^{\circ} \mathrm{C}$ which may be ascribed to a correspondingly small proportion of unconstrained material. For the supposedly unconstrained sample although the main melting transition occurs at $141.6^{\circ} \mathrm{C}$, a significant high temperature shoulder persists to a temperature of $154^{\circ} \mathrm{C}$. This appears to display a double transition, related to the formation and melting of the hexagonal phase, as observed for the constrained fibers suggesting that a significant proportion of the sample does appear to be subject to some form of constraint. This effect disappears when short lengths of fiber $(1-2 \mathrm{~mm})$ are used; they display only a single melting peak without any sign of a high temperature shoulder. It is not unreasonable to suppose that when longer fibers were simply rolled into a ball and placed into a DSC pan certain regions within them may not have been able to relax fully and so experienced some degree of constraint.

Changing the scan rate employed for constrained melting experiments informs on the influence of any 


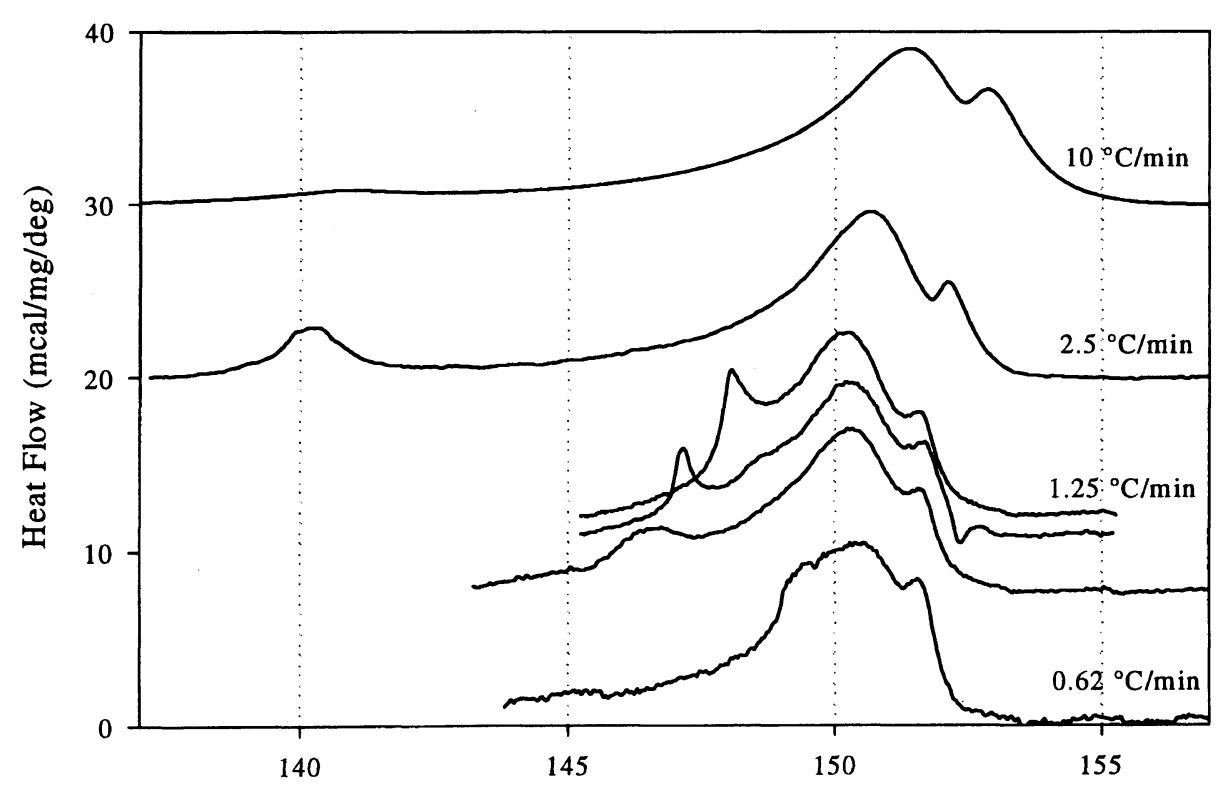

Figure 2. Effect of heating rate on the constrained melting of Tekmilon fibers.

reorganization and superheating on the observed melting points. Figure 2 shows endotherms recorded for scan rates of $0.625,1.25,2.5$, and $10 \mathrm{~K} \mathrm{~min}^{-1}$. At the lowest heating rate used, $0.625 \mathrm{~K} \mathrm{~min}^{-1}$, the main melting peak at $151^{\circ} \mathrm{C}$ has shoulders at $149^{\circ} \mathrm{C}$ and $152^{\circ} \mathrm{C}$. When the heating rate is increased to $1.25 \mathrm{~K} \mathrm{~min}^{-1}$ a low temperature endotherm is present at $147^{\circ} \mathrm{C}$, while the main melting peak and its high temperature shoulder occur at approximately the same temperatures as before. Three separate peaks can still be observed as the heating rate is increased further with the lowest peak moving to $\sim 140^{\circ} \mathrm{C}$ and, for the highest heating rate of $10 \mathrm{~K} \mathrm{~min}^{-1}$, being much diminished in size. This change suggests that, for the two lowest scan rates, the peak observed is due to material which has reorganized after melting at $\sim 140^{\circ} \mathrm{C}$, recrystallizing under a degree of constraint and finally melting at $146-148^{\circ} \mathrm{C}$. Some variability in the degree of constraint is suggested by this range of temperatures for the lowest peak found for repeated scans, at $1.25 \mathrm{~K} \mathrm{~min}^{-1}$, on fresh samples and shown in Figure 2. The same endotherms show consistency for the position and shape of the second and third endotherms, at and just above $\sim 151^{\circ} \mathrm{C}$. The slight increase with heating rate is an indication that the temperatures recorded are little affected by superheating which would cause them to rise for faster scan rates. The relative size of these two peaks is in accord with known behavior for successive transformation of orthorhombic to hexagonal phases then melting of the latter. This is evidence that the fibers have remained constrained until they melted. In combination with the X-ray data of Tsubakihara et al ${ }^{7,8}$ which show the stability of the hexagonal phase in such experiments, it follows that it must melt to a highly aligned state. This will tend to relax and when it does so the remaining material in the hexagonal phase will become unstable, the molten volumes will widen and consume the surviving solid isothermally.

\section{Morphological Examination}

The morphology of as-received Tekmilon fiber, following permanganic etching, is presented in Figure 3.
The appearance of a typical longitudinal section, as in Figure $3 \mathrm{a}$, is fibrillar with a suggestion of small inclusions of transverse recrystallized lamellae in agreement with previous observations. ${ }^{13,5}$ In transverse section (Figure $3 \mathrm{~b}$ ), the microstructure-here viewed at a slight angle to emphasize relief - is highly pitted on a scale of $1 \mu \mathrm{m}$. This is typical of high modulus polyethylene fibers following permanganic etching. The pitting is a consequence of the presence of narrow linear regions deficient in density, i.e., containing excess free volume, which are penetrated preferentially and opened out by the etchant. ${ }^{4,5}$

Constrained samples heated at $1.25 \mathrm{~K} \mathrm{~min}^{-1}$ to $153^{\circ} \mathrm{C}$, a temperature between the two major peaks, i.e., in the hexagonal-stable region, then immediately quenched, reveal a longitudinal microstructure as in Figure $4 \mathrm{a}$. From long thin inter-connecting 'spines', which have not melted, emerge transverse lamellae characteristic of polymer which had melted but then recrystallized epitaxially on cooling to produce so-called shish-kebabs but better known as row structures. That these 'spines' are generally present and that lamellar traces are perpendicular to them show that they are really sections through a honeycomb of walls (surrounding the craters in etched cross-sections) mostly extending into the paper from which lamellae grow outwards approximately parallel to the page. This is what has been observed for compacted Certran fibers ${ }^{6}$ where the later stages of melting leave the boundary walls of the craters surviving; for Tekmilon it would be expected, from cross-sections such as Figure 3b, that these would have a honeycomb geometry. Were the 'spines' truly linear, they would have nucleated lamellae growing out in all directions, as is discussed later, but is not generally observed. The length of the 'spines' at several $\mu$ m much exceeds the molecular length and is a novel morphological feature for polymer fibers. It is much greater than crystal sizes inferred for oriented ultra high modulus polyethylene from X-ray data. ${ }^{14}$

The effect of holding the sample for longer times at $153^{\circ} \mathrm{C}$ prior to quenching in liquid nitrogen is to produce 


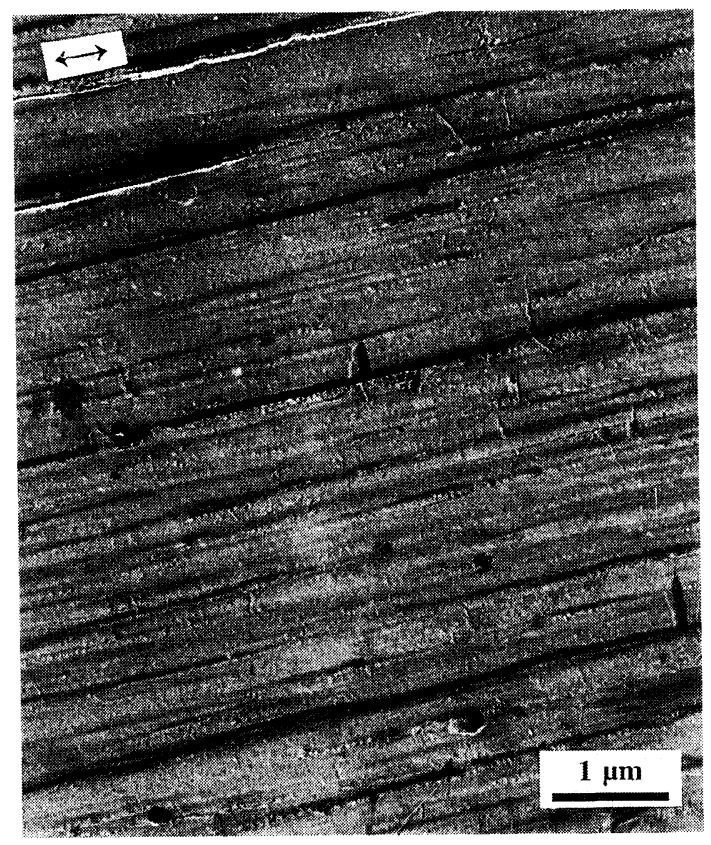

(a)

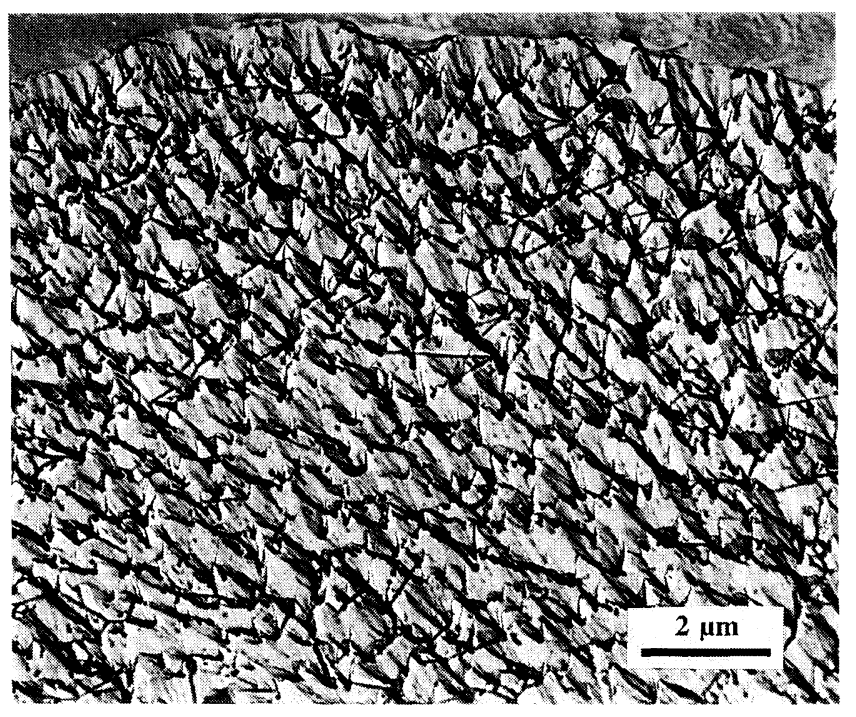

(b)

Figure 3. (a) Longitudinal view of the initial morphology of Tekmilon fibers; metal-shadowed replica of etched surface. (b) Transverse view of initial morphology of a Tekmilon fiber; metal-shadowed replica of etched surface.

narrower 'spines' which are farther apart on average (Table II). The 'apparent spine separation' is the projected centre-to-centre distance measured on the micrograph ignoring any differences in height perpendicular to the page.

Figures $4 b$ and $4 c$ show longitudinal views of samples held for $30 \mathrm{~s}$ and $5 \mathrm{~min}$ respectively before quenching. The widening separation is evidence of an evolving process whereby material at the edges of the fibrillar 'spines' is melting, from the hexagonal phase to an ordered melt, relaxing, then forming the surrounding epitaxially-recrystallized matrix on cooling. Figure $4 \mathrm{c}$ is of the last stages of this sequence.

There are two reasons for this sequence of events. First, the Gibbs free energy of a stressed or density-

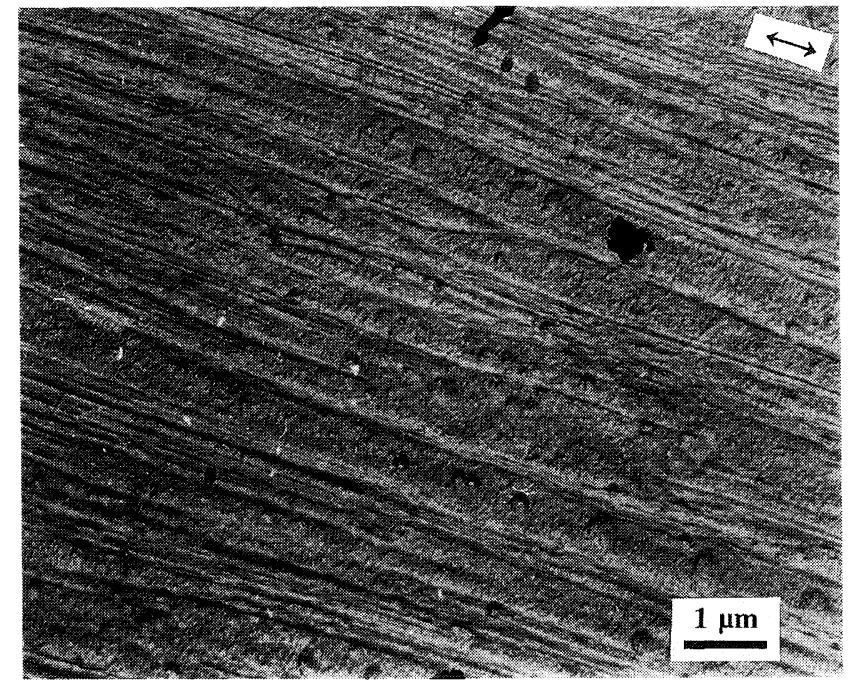

(a)

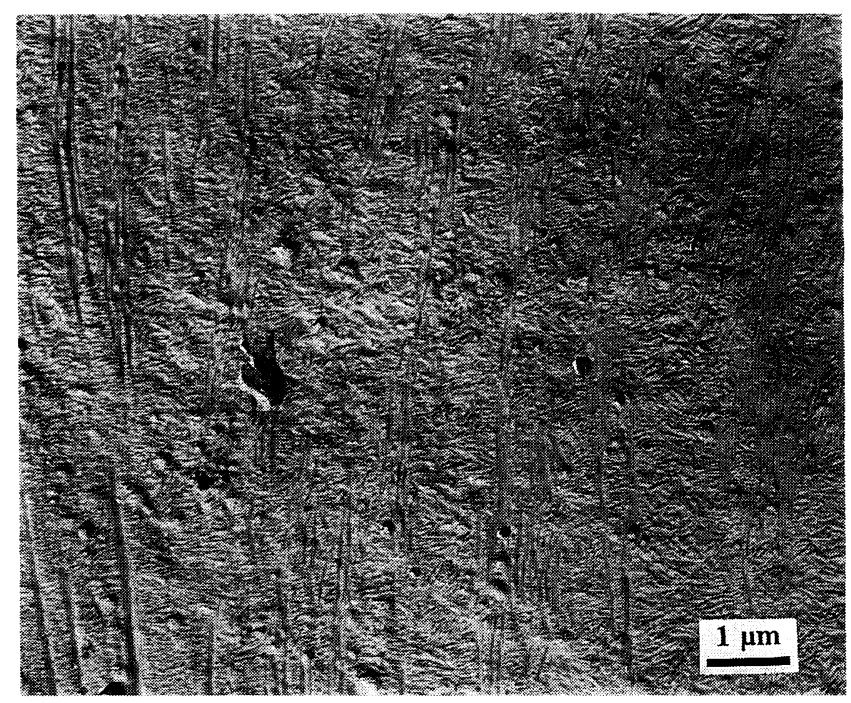

(b)

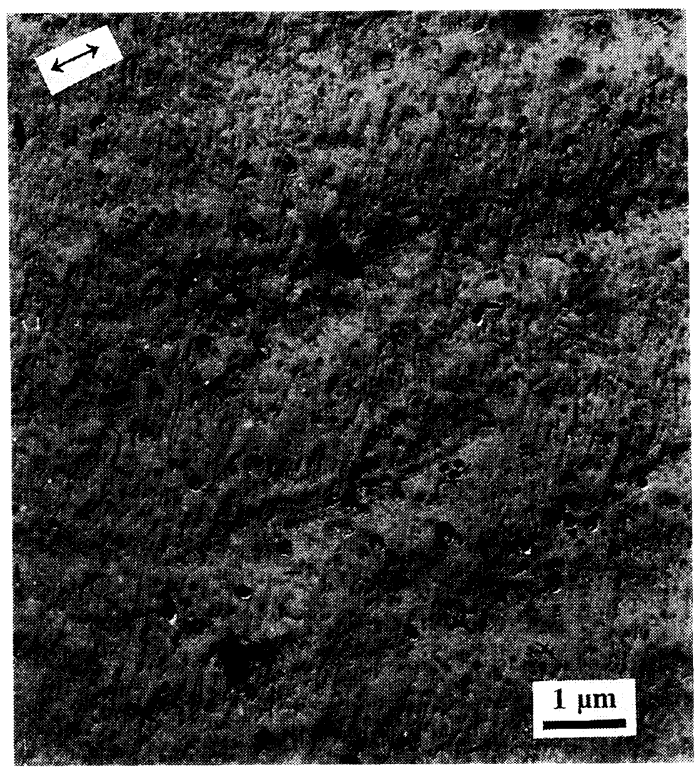

(c)

Figure 4. (a) Longitudinal view of Tekmilon fiber sample heated to $153^{\circ} \mathrm{C}$; metal-shadowed replica of etched surface.(b) Longitudinal view of a sample heated to $153^{\circ} \mathrm{C}$ and held for $30 \mathrm{~s}$ before quenching; metal-shadowed replica of etched surface. (c) Longitudinal view of a Tekmilon fiber heated to $153^{\circ} \mathrm{C}$ and held for $5 \mathrm{~min}$ before quenching; metal-shadowed replica of etched surface.

Polym. J., Vol. 31, No. 9, 1999 
Table II. Increase of apparent spine separation with holding time at $153^{\circ} \mathrm{C}$

\begin{tabular}{cccc}
$\begin{array}{c}\text { Holding time } \\
\text { at } 15 \mathrm{C} \mathrm{s}^{-1}\end{array}$ & 0 & 30 & 300 \\
\hline $\begin{array}{c}\text { Apparent spine } \\
\text { separation } / \mu \mathrm{m}\end{array}$ & $0.35 \pm 0.25$ & $0.5 \pm 0.25$ & $2.4 \pm 0.3$
\end{tabular}

deficient solid will be raised and its melting point lowered accordingly. A gradient of melting point results within the sample implying that only part will be molten at a given temperature. The second and possibly more important factor is that melting can only occur when there is sufficient free volume available for the melt to be able to form. Both criteria coincide to make the last regions to crystallize, i.e., the centers of the craters, the first to melt. Initially this melt must be highly aligned to be in equilibrium with the hexagonal phase otherwise the melting point would be lower - as is probably the case for Certran fibers. Being aligned it will experience retractive forces, arising from conformational energy considerations, which the specimen constraints are unlikely to be able to contain, contrary to the situation during processing. However, any randomization of the melt will make both ordered melt and hexagonal phase thermodynamically unstable. The melt/crystal boundary will thus be caused to spread outwards isothermally at a speed governed by the rate of molecular relaxation from the highly aligned state. Isothermal melting of the whole sample contrasts with the usual circumstances whereby only that part of the sample whose melting point has been exceeded is molten at a given temperature. The last material to melt will essentially be the first which crystallized, i.e., that which delineates the boundaries of the etched craters and appears as 'spines' in the cross-sections illustrated in Figures $4 \mathrm{a}, 4 \mathrm{~b}$, and 8.

The necessity of having the hexagonal phase in equilibrium with an aligned melt did not feature in a previous discussion ${ }^{15}$ of the melting of Spectra polyethylene fiber.

The application of stress is not itself a reason for 'stabilizing the orthorhombic phase' as is claimed because it will raise the Gibbs free energy of the crystal. The high melting point has to result from decreased conformational entropy of the melt ${ }^{12}$ which stress causes, with an upper limit given approximately by equating the fractional increase in melting point to the fractional decrease in the entropy of fusion when the melt has zero conformational entropy. Those authors ${ }^{15}$ also assumed, without the benefit of morphological evidence as reported here, that the partly molten fibril 'would consist of very fine crystal cores.' In our experience, ${ }^{5.13}$ Spectra fibers show the same kind of cratered cross-sections after etching as other high modulus polyethylene fibers, albeit with their own characteristic details. The higher melting regions would, accordingly, also be of honeycomb geometry.

An overall impression of the nature of the samples following heat treatment is given by the low magnification view of Figure 5, in which the fibers can be seen to have undergone significant deformation and adapted to the $\mathrm{V}$-shaped groove of the spool around which they were

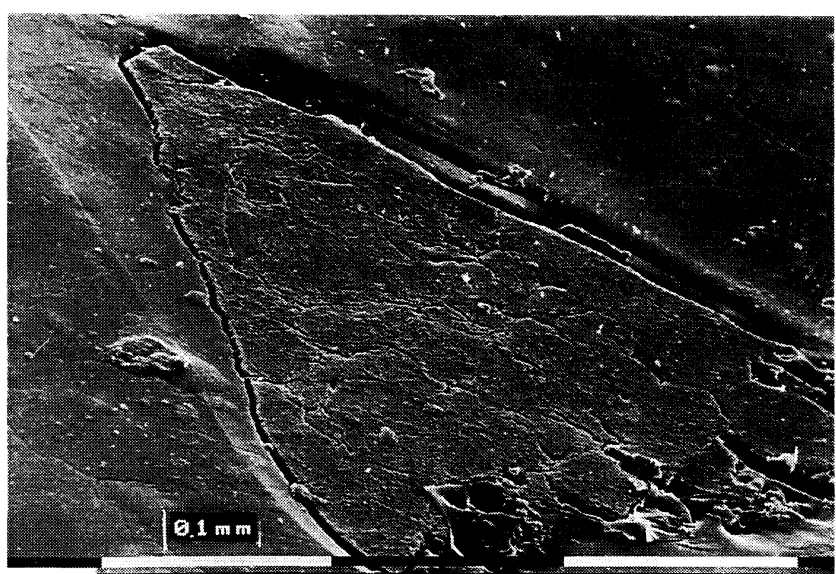

Figure 5. Scanning electron micrograph of a sample of a bundle of Tekmilon fibers heated to $153^{\circ} \mathrm{C}$, held for $30 \mathrm{~s}$ and quenched; etched surface.

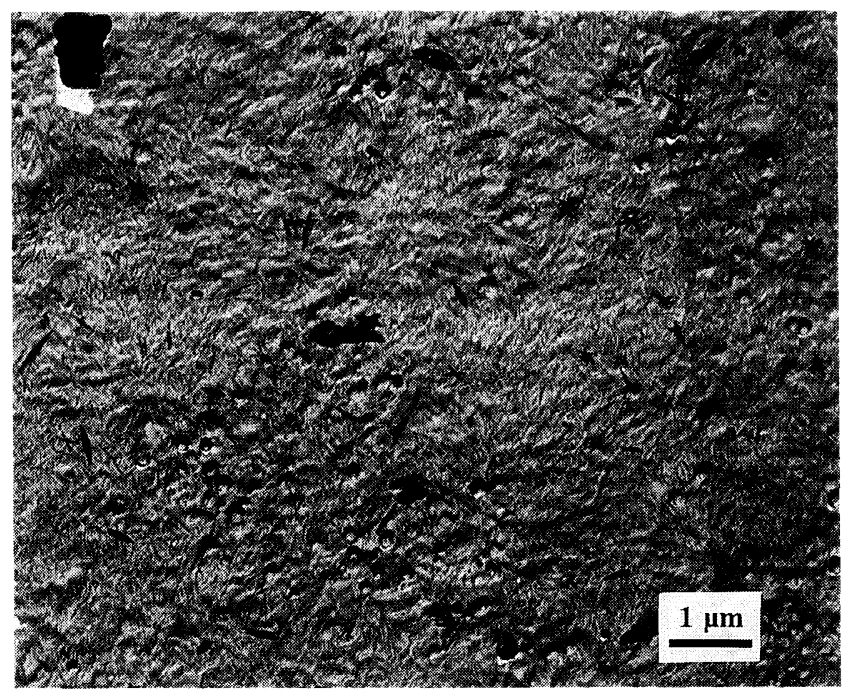

Figure 6. Transverse view of Tekmilon fiber displaying banded growth after being heated to $168^{\circ} \mathrm{C}$ and quenched; metal-shadowed replica of etched surface.

wrapped. Note that the boundaries between individual fibers in the bundle seem to have disappeared in certain areas, suggesting that their external surfaces have fused together.

After the constrained fibers have completely passed through the melting transitions of the hexagonal phase all trace of the original orientation and structure is lost. This is evident in Figure 6 from the presence of banded spherulitic areas within the recrystallized morphologies. These can only have formed by crystallization of an isotropic melt.

The type of morphology seen in the partly melted specimens (Figure 4) is characteristic of polymers which have crystallized from linear nuclei forming so called 'shish-kebab' or row structures. ${ }^{16}$ They are commonly encountered from a melt which has been oriented or strained in such a way as to produce linear nuclei. In this system however a strained melt is not of the essence of the formation of the row structures. The situation is, rather, akin to that investigated previously ${ }^{4,6}$ for compacted polymers. Transverse lamellae form from the molten part of the system nucleating on the adjacent 


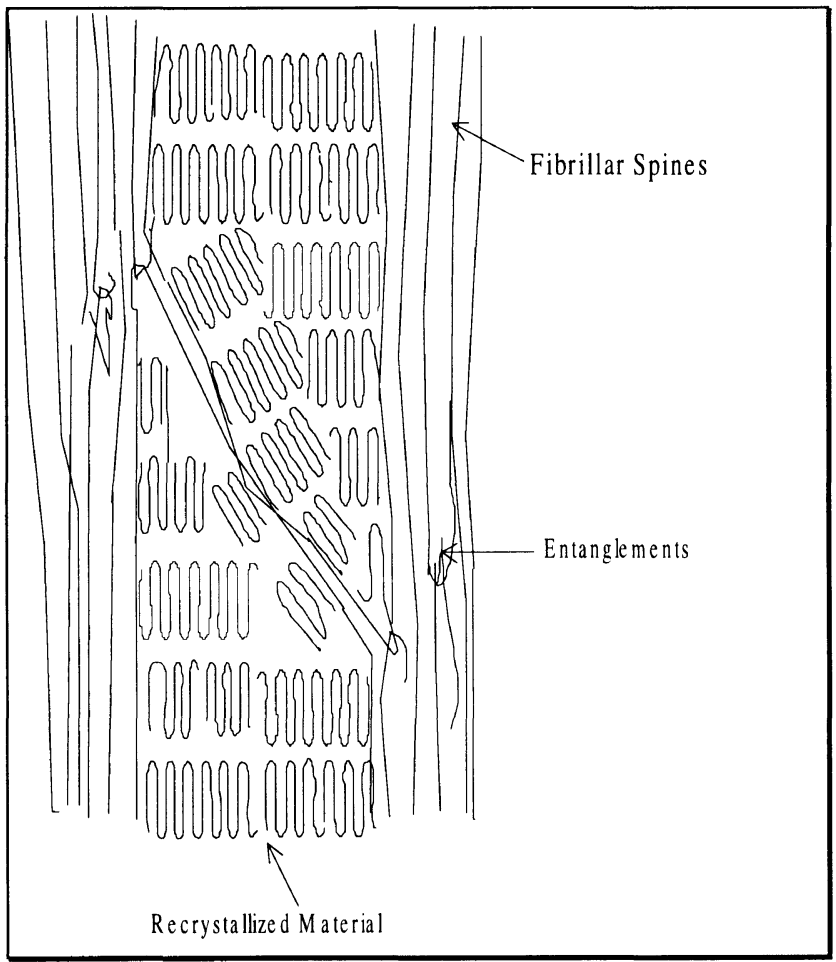

Figure 7. Schematic of internal fiber structure following partial melting.

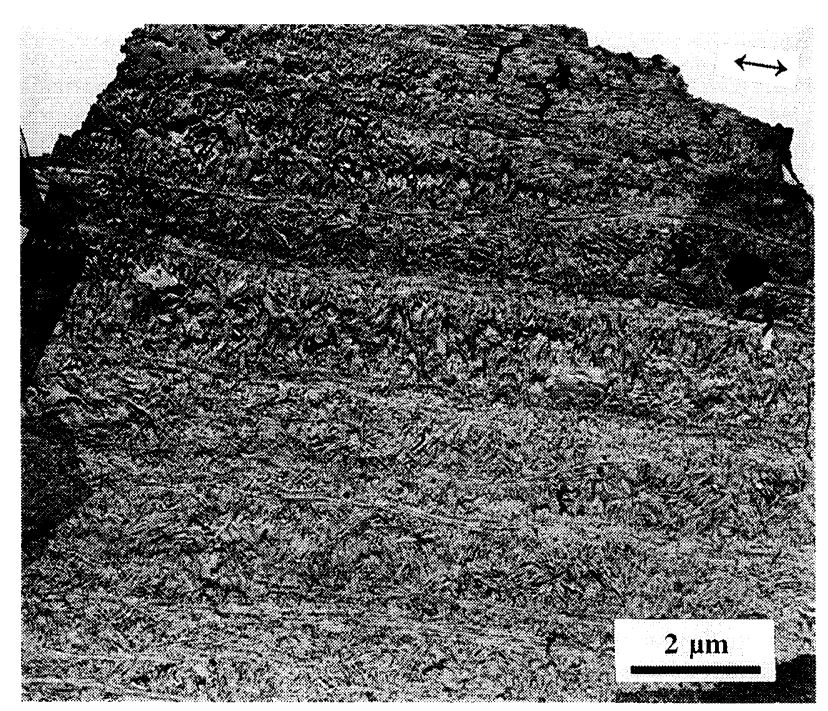

Figure 8. Longitudinal view of Tekmilon fibers cooled from $153^{\circ} \mathrm{C}$ at a rate of $160 \mathrm{~K} \mathrm{~min}^{-1}$; metal-shadowed replica of etched surface.

oriented solid, in this case boundary walls, with the same $c$ axis orientation and growing radially along the $b$ axis, the fastest growth direction; other directions may also be nucleated but do not propagate. ${ }^{6}$ Close examination of the recrystallized regions fails to disclose any join at which the two growth fronts from adjacent 'spines' converged. Nor are there signs of voids or other defects indicative of molecular segregation or insufficient melt fully to consolidate the structure as is encountered in compacted polypropylenes. ${ }^{17,18}$ The differences are due partly to molecular segregation (of poorly isotactic molecules) and partly to the more exacting constraints in the polypropylene systems.

Figure 7 is an impression of the structure of the 'spines' and recrystallized material in cross-section which displays the extended-chain nature of the 'spines' and their connectivity imposed by physical entanglements. Recrystallized material has nucleated from the walls as folded chain lamellae.

Hitherto, all samples have been cooled in liquid nitrogen. Figure 8 is of a longitudinal section of the morphology produced by the alternative procedure of cooling in the DSC at the fastest controllable rate, i.e., $160^{\circ} \mathrm{K} \mathrm{min}^{-1}$. There is an overall similarity to previous observations but a difference in that the recrystallized material has developed banding parallel to the 'spines'. Banding is indicative of polyethylene crystallized at lower temperatures and shows that this second procedure gave more effective cooling than did dropping the DSC pan into liquid nitrogen, doubtless due to the insulation provided by the ensuing coating of bubbles. Concomitantly, the lower crystallization temperature has increased the rate of nucleation in the inter-fibrillar matrix so that in contrast to Figure 4 spherulitic growth has nucleated in it spontaneously. The associated inclination of lamellae is a consequence of observation more or less down the growth direction so that the obliquity of the fold surfaces is (partly) revealed. The absence of this feature previously, i.e., in Figure 4 , confirms that, under those conditions, growth was outward from walls and in the plane of the paper rather than from linear nuclei and, as here, partly out of the page. This evidence underpins the earlier inference that the apparent 'spines' are generally walls which extend through the plane of the paper. Only in the very last stages of melting would one expect to find linear remnants of the original stretched molecular network and possibly not even then.

\section{CONCLUSIONS}

1. The highly aligned Tekmilon polyethylene fibers contain high-melting longitudinal regions parallel to the fiber axis and continuous over many $\mu \mathrm{m}$.

2. In addition, there is lateral disorder on the scale of $\sim 1 \mu \mathrm{m}$ revealed as craters by permanganic etching. This is a consequence of periodic increases in free volume and reduced density related to processing conditions.

3. Fibers held at constant length enter the hexagonal phase prior to melting. When they do melt it is to a highly aligned state whose subsequent relaxation renders the remaining solid unstable. Further melting then proceeds isothermally at a rate governed by that of molecular relaxation.

4. The last regions to melt are identified with the locations of the stretched molecular network from which crystallization was nucleated when fibers formed. This accords with the new model ${ }^{5}$ of the structure of polymeric fibers.

Acknowledgments. The authors are greatly indebted to Prof. Keisuke Kaji of the University of Kyoto for the Tekmilon fibers used and to Professor Munehisa Yasuniwa of Fukuoka University for helpful advice. This research formed part of the programme 'Fundamentals of Polymer Crystallization' funded by NEDO. 


\section{REFERENCES}

1. F. C. Frank, Proc. R. Soc. London, A, 282, 9 (1964).

2. F. C. Frank, Proc. R. Soc. London, A, 319, 127 (1970).

3. A. G. Gibson, G. R. Davies, and I. M. Ward, Polymer, 19, 683 (1978).

4. D. C. Bassett, R. H. Olley, P. J. Hine, and I. M. Ward, J. Mater. Sci., 28, 1107 (1993).

5. M. I. Abo el Maaty, R. H. Olley, and D. C. Bassett, J. Mater. Sci., 34, 1975 (1999).

6. M. A. Kabeel, R. H. Olley, D. C. Bassett, P. J. Hine, and I. M. Ward, J. Mater. Sci., 30, 601 (1995).

7. S. Tsubakihara, A. Nakamura, and M. Yasuniwa, Polym. J., 23, 1317 (1991).

8. S. Tsubakihara, A. Nakamura, and M. Yasuniwa, Polym. J., 28, 489 (1996).

9. D. C. Bassett, S. Block, and G. J. Piermarini, J. Appl. Phys., 45,
4146 (1974).

10. A. J. Pennings and A. Zwijnenburg J. Polym. Sci., Polym. Phys. Ed., 17, 1011 (1979)

11. N. A. J. M. van Aerle and P. J. Lemstra, Polym. J., 20, 131 (1988).

12. A. Peterlin, in "Flow-Induced Crystallization in Polymer Systems," R. L. Miller, Ed, Gordon Breach., London, 1979, p 1.

13. M. I. Abo el Maaty, Ph.D. Thesis, University of Mansoura, Egypt (1995).

14. J. Clements and I. M. Ward, Polymer, 24, 27 (1983).

15. S. Rastogi and J. A. Odell, Polymer, 34, 1523 (1993).

16. D. C. Bassett, "Principles of Polymer Morphology," Cambridge University Press, Cambridge, 1981.

17. M. I. Abo el Maaty, D. C. Bassett, R. H. Olley, P. J. Hine, and I. M. Ward, J. Mater. Sci., 31, 1157 (1996).

18. J. Teckoe, D. C. Bassett, R. H. Olley, P. J. Hine, and I. M. Ward, J. Mater. Sci., 34, 2065 (1999). 